\title{
IDENTIFIKASI FAKTOR PENCEGAH PENULARAN TB PARU DALAM RUMAH DI WILAYAH KERJA PUSKESMAS WONOKUSUMO SURABAYA TAHUN 2016
}

\author{
Vebrina Arvianti, Umi Rahayu, Khambali
}

\begin{abstract}
Surabaya ranked the first position for the incident of Pulmonary TB in East Java. In Wonokusumo health center, the number of patients with pulmonary TB increased from 2014 to 2015 by 57\% and treatment success rate in 2015 reached 96\%. This study aims to determine the relationship of behavior with home sanitation to prevent pulmonary tb infection in the house.

This is a Case Control study with study population was family member of patients with pulmonary TB. The sample size was 49 cases and 49 controls. The sampling technique used multistage sampling method. Technique of collecting data used questionnaires and home observation sheets. Data was analyzed by SPSS Chis-Square test.

This study shows that $\rho(0,000)<a(0.05)$, which means there was relationship between behavior with home sanitation condition to prevent pulmonary TB transmission at home.

The conclusion of this study is that family members had poor level of knowledge, attitudes, and sanitation condition. $61.2 \%$ did not meet the standard and there was relationship of behavior and home sanitation. the society should add information about pulmonary TB condition and home sanitary as well as conducting routine mass cleaning program. Wonokusumo health center needs to provide counseling and formation of cadres that serves to provide information and motivation to pulmonary TB patients.
\end{abstract}

Keywords : Behavior, home sanitation condition, pulmonary tuberculosis

\section{PENDAHULUAN}

Manusia dalam kelangsungan hidupnya di dunia ini menuntut beberapa kebutuhankebutuhan pokok yang harus dia miliki sepanjang hidupnya. Keluarga yang meningkat pada populasi penduduk meningkatkan pula kebutuhan akan tempat tinggal yang memenuhi syarat hidup sehat.

Keputusan Menteri Kesehatan RI No. 829/Menkes/SK/VII/1999 rumah adalah bangunan yang berfungsi sebagai tempat tinggal atau hunian dan sarana pembinaan keluarga. (Santoso dan Muchsin dalam Kasjono,2011:1). Menurut WHO dalam Kasjono (2011) mengemukakan rumah sehat adalah suatu keadaan yang sempurna baik fisik, mental maupun sosial budaya, bukan hanya keadaan yang bebas dari penyakit dan kelemahan (kecacatan). Berdasarkan pengertian diatas Rumah sehat diartikan sebagai tempat berlindung/bernaung dan tempat untuk beristirahat, sehingga menumbuhkan kehidupan yang sempurna baik fisik, rokhani maupun sosial. (Istiqomah dan Hanas dalam Kasjono,2011:22)

Masalah rumah dan pemukiman di Indonesia berakar dari pergeseran konsentrasi penduduk dari desa ke kota. Kualitas pemukiman penduduk dianggap rendah dan tidak memenuhi standart hidup yang layak. Pembangunan yang rendah kualitasnya dapat berdampak buruk terhadap kesehatan dan keamanan penghuninya sehingga dapat memicu penyakit yang berbasis lingkungan seperti TB Paru.

Dalam masyarakat yang hidupnya berdesak-desakan, tinggal dirumah yang sumpek, kurang ventilasi udara, kurang cahaya matahari, hal ini menyebabkan kuman TB Paru bertebaran dalam udara. (Nadesul, 1995: 1). Rumah sehat dapat membantu mengurangi bakteri yang berada pada lantai atau peralatan rumah lainnya. Genteng kaca dapat membantu memasukkan sinar ultraviolet matahari masuk kedalam kamar dan mengeliminasi kuman atau bakteri yang berada pada lantai atau tempat tidur. (Achmadi, 2012: 125).

Perilaku manusia pada hakekatnya adalah suatu aktivitas dari manusia itu sendiri. Menurut Bloom (1908) dalam Notoatmojo (2011) mengemukakan bahwa seorang ahli psikolog pendidikan membagi perilaku itu kedalam tiga domain (ranah/kawasan). Faktor perilaku meliputi pengetahuan, sikap, dan tindakan. (Notoatmodjo,2011: 135-146).

Faktor perilaku tersebut sangat berpengaruh dengan kesembuhan dan pencegahan untuk tidak terinfeksi TB Paru. Penderita TB Paru berdampak bagi para anggota keluarga lainnya maka dari itu perilaku para anggota keluarga yang harus diterapkan untuk mencegah penularan TB Paru dalam rumah.

Perilaku yang diterapkan meliputi membuka jendela secara rutin karena untuk penyembuhan TB Paru diperlukan udara yang segar dan udara harus mengalir, udara harus 
senantiasa bertukar dengan udara yang baru dan sinar matahari dapat memasuki semua ruangan yang ada di rumah, lantai rumah harus rajin disapu atau dipel secara rutin, diberi larutan lisol bahan pembunuh kuman dan menjemur kasur penderita langsung dibawah sinar matahari. (Nadesul.1995)

Berdasarkan laporan di wilayah kerja puskesmas Wonokusumo Surabaya diperoleh informasi bahwa jumlah penderita TB Paru di wilayah kerja puskesmas Wonokusumo pada tahun 2014 yaitu sebanyak 34 orang yang tercatat. Pada tahun 2015 penyakit TB Paru mengalami kenaikan yang meningkat yaitu sebanyak 60 orang yang tercatat. Kenaikan jumlah penderita TB Paru ini dari tahun 2014 ke tahun 2015 sebesar 57\% . Keberhasilan pengobatan sepanjang tahun 2015 sebanyak 58 orang yang dinyatakan sembuh sehingga memperoleh prosentase sebesar sebesar $97 \%$. Pada tahun 2016 tercatat penderita TB Paru bulan Januari - Juni sebanyak 35 sebesar $58 \%$.

Penyakit TB Paru ini termasuk penyakit yang berbasis lingkungan terutama yang berkaitan dengan tempat tinggal penderita yaitu rumah yang tidak memenuhi syarat kesehatan. Sesuai laporan yang diperoleh dari laporan Puskesmas Wonokusumo Surabaya pada tahun 2014 terdapat 242 rumah sehat dan 19 rumah yang belum sehat dari 261 rumah yang diperiksa. Pada tahun 2015 terdapat 771 rumah sehat dan 87 rumah yang belum sehat dari 858 rumah yang diperiksa. Pada tahun 2016 rumah sehat menurut kelurahan puskesmas wonokusumo dengan jumlah seluruh rumah yang diperiksa sebesar 10234, rumah yang memenuhi syarat sebesar 7990 (78\%), jumlah rumah yang belum memenuhi syarat sebesar 2244, rumah dibina sebesar 2078 (20\%), rumah dibina yang memenuhi syarat sebesar 1342
(65\%) sehingga total rumah sehat yang memenuhi syarat sebesar 9332 (91\%).

Tujuan Umum dari penelitian ini yaitu Untuk mengetahui hubungan antara perilaku dengan keadaan sanitasi rumah untuk mencegah penularan TB Paru dalam rumah diwilayah kerja puskesmas Wonokusumo Surabaya.

\section{METODE PENELITIAN}

Penelitian ini bersifat analitik karena bertujuan untuk mengetahui hubungan perilaku para anggota Penderita TB Paru dengan keadaan sanitasi rumah di wilayah kerja Puskesmas Wonokusumo Surabaya.

Dalam penelitian ini populasinya adalah anggota keluarga penderita TB Paru di daerah wonokusumo Surabaya sebanyak 56. Dengan pengambilan sampel pada penelitian ini sebesar 49 sampel dan 49 kontrol. Pengumpulan data dalam penelitian ini dilakukan dengan beberapa cara, yaitu :

1. Data Primer

Data yang dikumpulkan langsung dengan kuisioner, observasi dan pengukuran

2. Data Sekunder
a. Kantor Dinas Kesehatan Surabaya tentang Profil Kesehatan Puskesmas Wonokusumo mengenai Penyakit Tb Paru
b. Puskesmas Wonokusumo Surabaya mengenai data jumlah penderita TB Paru dan data Rumah sehat.

Metode analisis data yang digunakan pada penelitian ini adalah metode Chi square yang sesuai dengan SPPS.

\section{hASIL PENELITIAN DAN PEMBAHASAN}

Dari hasil penelitian didapatkan hasil tingkat pengetahuan, sikap, tindakan anggota keluarga dan hubungan perilaku anggota keluarga dengan keadaan sanitasi rumah sebagai berikut :

\section{Tingkat Pengetahuan Anggota Keluarga}

Tabel 1

Hasil Penilaian Tingkat Pengetahuan Anggota Keluarga

\begin{tabular}{llcccc}
\hline No. & Tingkat Pengetahuan & \multicolumn{3}{c}{ Sampel } & \multicolumn{3}{c}{ Kontrol } \\
\cline { 3 - 6 } & & $\mathrm{n}$ & Prosentase (\%) & $\mathrm{n}$ & Prosentase (\%) \\
\hline 1. & Kurang & 25 & $51,0 \%$ & 9 & $18,4 \%$ \\
\hline 2. & Cukup & 18 & $36,7 \%$ & 15 & $30,6 \%$ \\
\hline 3. $\quad$ Baik & 6 & $12,2 \%$ & 25 & $51 \%$ \\
\hline Jumlah & 49 & $100 \%$ & 49 & $100 \%$ \\
\hline Sumber : Data primer & &
\end{tabular}




\section{Sikap Anggota Keluarga}

Tabel 2

Hasil Penilaian Sikap Anggota Keluarga

\begin{tabular}{clcccc}
\hline No. & Sikap Anggota Keluarga & \multicolumn{2}{c}{ Sampel } & \multicolumn{2}{c}{ Kontrol } \\
\cline { 3 - 6 } & & $\mathrm{n}$ & Prosentase (\%) & $\mathrm{n}$ & Prosentase (\%) \\
\hline 1. & Kurang & 26 & $53,1 \%$ & 2 & $4,1 \%$ \\
\hline 2. & Cukup & 18 & $36,7 \%$ & 12 & $24,5 \%$ \\
\hline 3. & Baik & 5 & $10,2 \%$ & 35 & $71,4 \%$ \\
\hline & $\quad$ Jumlah & 49 & $100 \%$ & 49 & $100 \%$ \\
\hline
\end{tabular}

Sumber data : primer

Tindakan Anggota Keluarga

Tabel 3

Hasil Penilaian Tindakan Anggota Keluarga

\begin{tabular}{llcccc}
\hline & & Tindakan & \multicolumn{2}{c}{ Sampel } & \multicolumn{2}{c}{ Kontrol } \\
\cline { 3 - 6 } & & $\mathrm{n}$ & Prosentase (\%) & $\mathrm{n}$ & Prosentase (\%) \\
\hline 1. & Kurang & 23 & $46,9 \%$ & 7 & $14,3 \%$ \\
\hline 2. & Cukup & 21 & $42,9 \%$ & 15 & $30,6 \%$ \\
\hline 3. & Baik & 5 & $10,2 \%$ & 27 & $55,1 \%$ \\
\hline & Jumlah & 49 & $100 \%$ & 49 & $100 \%$ \\
\hline
\end{tabular}

Sumber : Data primer

\section{Keadaan Sanitasi Rumah}

Tabel 4

Hasil Penilaian Keadaan Sanitasi Rumah

\begin{tabular}{|c|c|c|c|c|}
\hline \multirow[t]{2}{*}{ No. Keadaan Sanitasi Rumah } & \multicolumn{2}{|c|}{ Sampel } & \multicolumn{2}{|c|}{ Kontrol } \\
\hline & $\mathrm{n}$ & Prosentase (\%) & $\mathrm{n}$ & Prosentase (\%) \\
\hline TMS & 30 & $61,2 \%$ & 12 & $24,5 \%$ \\
\hline 2. $\quad \mathrm{MS}$ & 19 & $38,8 \%$ & 37 & $75,5 \%$ \\
\hline Jumlah & 49 & $100 \%$ & 49 & $100 \%$ \\
\hline
\end{tabular}

Tingkat pengetahuan anggota keluarga adalah kurang sebesar 25 orang (51\%). Sikap anggota keluarga adalah kurang sebesar 26 orang $(53,1 \%)$. Tindakan anggota keluarga adalah kurang sebesar 23 orang (46,9\%). Keadaan sanitasi rumah yang tidak memenuhi syarat sebesar 30 orang $(61,25 \%)$ dan yang memenuhi syarat sebesar 19 orang $(38,8 \%)$

\section{Hubungan tingkat pengetahuan dengan Keadaan Sanitasi rumah}

Tabel 5

Hubungan Tingkat Pengetahuan Anggota Keluarga Dengan Keadaan Sanitasi Rumah

\begin{tabular}{|c|c|c|c|c|c|}
\hline \multirow[t]{2}{*}{ No } & \multirow{2}{*}{$\begin{array}{c}\text { Tingkat Pengetahuan Anggota } \\
\text { Keluarga }\end{array}$} & \multicolumn{2}{|c|}{ Keadaan Sanitasi Rumah } & \multirow[t]{2}{*}{$\Sigma$} & \multirow[t]{2}{*}{$\rho$} \\
\hline & & TMS & MS & & \\
\hline 1. & Kurang & $\begin{array}{c}24 \\
24,5 \%\end{array}$ & $\begin{array}{c}10 \\
10,2 \%\end{array}$ & $\begin{array}{c}34 \\
34,7 \%\end{array}$ & \multirow{4}{*}{0,000} \\
\hline 2. & Cukup & $\begin{array}{c}12 \\
12,2 \%\end{array}$ & $\begin{array}{c}21 \\
21,4 \%\end{array}$ & $\begin{array}{c}33 \\
33,7 \% \\
\end{array}$ & \\
\hline 3. & Baik & $\begin{array}{c}6 \\
6,1 \% \\
\end{array}$ & $\begin{array}{c}25 \\
25,5 \% \\
\end{array}$ & $\begin{array}{c}31 \\
31,6 \% \\
\end{array}$ & \\
\hline & Total & $\begin{array}{c}42 \\
42,9 \%\end{array}$ & $\begin{array}{c}56 \\
57,1 \%\end{array}$ & $\begin{array}{c}89 \\
100 \%\end{array}$ & \\
\hline
\end{tabular}

Sumber : Data primer

Hasil analisis dengan uji Chi Square didapatkan bahwa Bila $\rho(0,000)<a(0,05)$ yang berarti ada hubungan antara tingkat pengetahuan anggota keluarga penderita TB Paru dengan keadaan sanitasi rumah untuk mencegah penularan TB Paru dalam rumah.
Pengetahuan yang baik akan kondisi rumah yang sehat tidak akan terjadi penularan penyakit hal ini sesuai dengan teori Winslow dan APHA dalam buku penyehatan pemukiman rumah (Kasjono,2011) yaitu mencegah penularan penyakit dalam rumah. 
Penelitian ini sejalan dengan penelitian Niko Rianda Putra 2011 yang menyatakan terdapat hubungan yang bermakna antara tingkat pengetahuan responden dengan kejadian TB.

Menurut Khadijah Azhar dan Dian Perwitasari dalam penelitiannya yang berjudul Kondisi Fisik Rumah Dan Perilaku Dengan Prevalensi Tb Paru Di Propinsi DKI Jakarta, Banten Dan Sulawesi Utara tahun 2013 mengatakan bahwa Latar belakang pengetahuan seseorang berdasarkan tingkat pendidikan yang dapat mempengaruhi perilaku seseorang. Perilaku seseorang berkaitan erat dengan pengetahuan yang dimilikinya. Pengetahuan tersebut diperoleh antara lain melalui pendidikan. Pendidikan itu sendiri adalah dasar terbentuknya perilaku seseorang sehingga pendidikan dikatakan sebagai faktor utama dan tingkat ekonomi yang mempengaruhi status kesehatan. Seseorang yang memiliki tingkat pendidikan yang tinggi akan memiliki pengetahuan dan sikap yang baik tentang kesehatan sehingga akan mempengaruhi perilakunya untuk hidup sehat. Tetapi masih terdapat juga pengetahuan anggota keluarga yang baik dengan kondisi rumah yang tidak memenuhi syarat hal ini bisa dikarenakan anggota keluarga mempunyai kesibukan dalam kesehariannya sehingga mereka tidak mengaplikasikan pengetahuan mereka dalam tindakan pembersihan rumah.

\section{Hubungan Sikap dengan Keadaan Sanitasi Rumah}

Tabel 6

Hubungan Sikap Anggota Keluarga Dengan Keadaan Sanitasi Rumah

\begin{tabular}{|c|c|c|c|c|}
\hline \multirow[t]{2}{*}{ No Sikap Anggota Keluarga } & \multicolumn{2}{|c|}{ Keadaan Sanitasi Rumah } & \multirow[t]{2}{*}{$\Sigma$} & \multirow[t]{2}{*}{$\rho$} \\
\hline & TMS & MS & & \\
\hline \multirow{2}{*}{ 1. $\quad$ Kurang } & 23 & 5 & 28 & \multirow{8}{*}{0,000} \\
\hline & $23,5 \%$ & $5,1 \%$ & $28,6 \%$ & \\
\hline \multirow[t]{2}{*}{ 2. $\quad$ Cukup } & 11 & 19 & 30 & \\
\hline & $11,2 \%$ & $19,4 \%$ & $30,6 \%$ & \\
\hline \multirow[t]{2}{*}{ 3. Baik } & 8 & 32 & 40 & \\
\hline & $8,2 \%$ & $32,7 \%$ & $40,8 \%$ & \\
\hline \multirow[t]{2}{*}{ Total } & 42 & 56 & 89 & \\
\hline & $42,9 \%$ & $57,1 \%$ & $100 \%$ & \\
\hline
\end{tabular}

\section{Sumber : Data primer}

Hasil analisis degan uji Chi Square didapatkan bahwa Bila $\rho(0,000)<a(0,05)$ yang berarti ada hubungan antara sikap anggota keluarga penderita TB Paru dengan keadaan sanitasi rumah untuk mencegah penularan TB Paru dalam rumah.

Sikap merupakan reaksi atau respons seseorang yang masih tertutup terhadap suatu stimulus atau objek. Penelitian yang telah dilakukan oleh Toni Lumban Tobing 2008 dari hasil penelitian tersebut Sikap mempunyai hubungan yang signifikan dengan potensi penularan TB Paru. Menurut Aviliana R. Wenas,2015 menyatakan Jika sikap masyarakat sudah baik maka masyarakat akan mudah untuk melakukan suatu perbuatan yang baik, tapi jika sikap ini masih kurang maka memiliki dampak yang buruk bagi derajat kesehatan masyarakat. Untuk merubah sikap, pengetahuan harus ditingkatkan dan pemerintah harus memberikan contoh yang baik kepada masyarakat agar perilaku hidup sehat dapat terlaksana.

\section{Hubungan Tindakan dengan Keadaan Sanitasi Rumah}

Tabel 7

Hubungan Tindakan Anggota Keluarga Dengan Keadaan Sanitasi Rumah

\begin{tabular}{|c|c|c|c|c|}
\hline \multirow[t]{2}{*}{ No Tindakan Anggota Keluarga } & \multicolumn{2}{|c|}{ Keadaan Sanitasi Rumah } & \multirow[t]{2}{*}{$\Sigma$} & \multirow[t]{2}{*}{$\rho$} \\
\hline & TMS & MS & & \\
\hline 1. Kurang & $\begin{array}{c}22 \\
22,4 \%\end{array}$ & $\begin{array}{c}8 \\
8,2 \%\end{array}$ & $\begin{array}{c}30 \\
30,6 \%\end{array}$ & \\
\hline Cukup & $\begin{array}{c}15 \\
15,3 \% \\
\end{array}$ & $\begin{array}{c}21 \\
21,4 \% \\
\end{array}$ & $\begin{array}{c}36 \\
36,7 \% \\
\end{array}$ & 0,000 \\
\hline 3. $\quad$ Baik & $\begin{array}{c}5 \\
5,1 \% \\
\end{array}$ & $\begin{array}{c}27 \\
27,6 \% \\
\end{array}$ & $\begin{array}{c}32 \\
32,7 \% \\
\end{array}$ & \\
\hline Total & $\begin{array}{c}42 \\
42,9 \%\end{array}$ & $\begin{array}{c}56 \\
57,1 \% \\
\end{array}$ & $\begin{array}{c}89 \\
100 \% \\
\end{array}$ & \\
\hline
\end{tabular}

Sumber : Data primer 
Hasil analisis dengan uji Chi Square didapatkan bahwa Bila $\rho(0,000)<a(0,05)$ yang berarti ada hubungan antara tindakan anggota keluarga penderita TB Paru dengan keadaan sanitasi rumah untuk mencegah penularan TB Paru dalam rumah.

Menurut Notoatmodjo,2011 suatu sikap belum otomatis terwujud dalam suatu tindakan (overt behavior). Untuk terwujudnya sikap menjadi suatu perbedaan nyata diperlukan faktor pendukung atau suatu kondisi yang memungkinkan antara lain adalah fasilitas. Disamping faktor fasilitas juga diperlukan faktor dukungan (support) dari pihak lain.

Hal ini sejalan dengan penelitian Aviliana R. Wenas, 2015 yang menyatakan terdapat hubungan antara tindakan dengan kejadian penyakit Tuberkolosis. Hal ini mendukung penelitian dari Niko Putra, 2011 yang menyatakan terdapat hubungan antara tindakan dengan kejadian penyakit Tuberkulosis Paru di Kota Solok. Tindakan yang masih kurang ini dapat menjadi salah satu sumber penularan, sehingga mata rantai penularan penyakit
Tuberkulosis ini sulit untuk diputuskan. Tindakan merupakan tahap akhir dari perilaku, sehingga tindakan yang baik atau yang kurang yang dilakukan oleh responden adalah pengaruh dari tingkat pengetahuan dan sikap responden.

Tindakan yang kurang merupakan faktor resiko untuk penyakit TB Paru, seperti tidak memeriksakan dahak walaupun sudah batuk lebih dari 3 minggu dan kondisi rumah yang tidak memenuhi syarat seperti kurangnya ventilasi dan cahaya matahari yang masuk kedalam rumah. Karena cahaya matahari dapat membunuh kuman terutama kuman Mycobacterium tuberculosis dengan kondisi tersebut dapat memperparah penyakit dan juga bisa menjadi sumber penularan. Untuk menjadikan tindakan yang baik masyarakat haruslah lebih sering dipaparkan dengan bagaimana, apa dan dampak dari penyakit TB Paru tersebut serta ada stimulan atau rangsangan yang baik dari Pemerintah untuk meningkatkan pengetahuan dan memberdayakan masyarakat.

Hubungan Perilaku dengan Keadaan Sanitasi Rumah

Tabel 8

Hubungan Perilaku Anggota Keluarga Dengan Keadaan Sanitasi Rumah

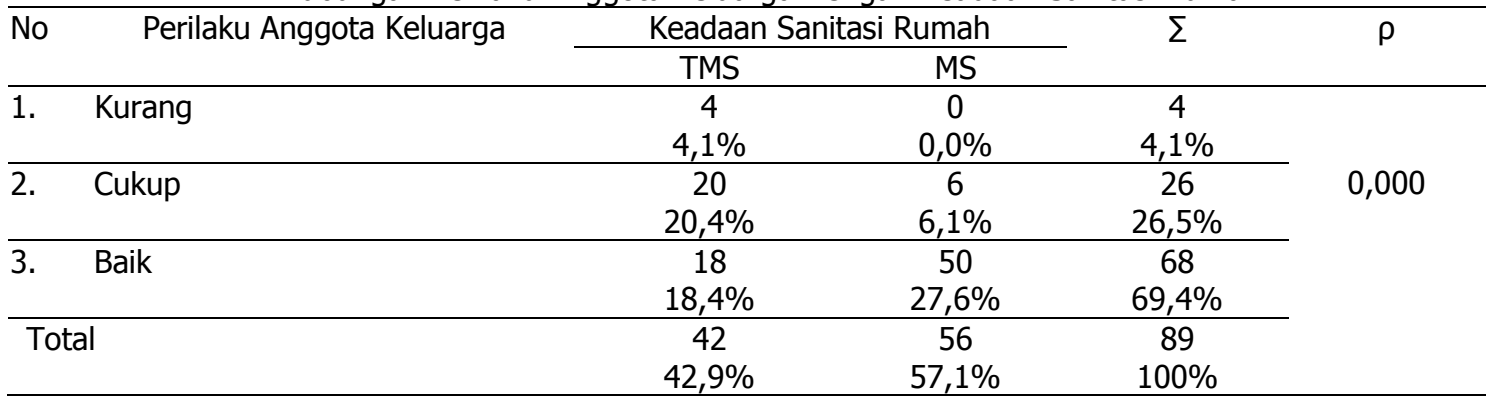

Sumber : Data primer

Hasil analisis dengan uji Chi Square didapatkan bahwa Bila $\rho(0,000)<a(0,05)$ yang berarti ada hubungan antara perilaku anggota keluarga penderita TB Paru dengan keadaan sanitasi rumah untuk mencegah penularan TB Paru dalam rumah.

Menurut Notoatmodjo, 2011 mengatakan Perilaku manusia pada hakikatnya adalah suatu aktivitas dari manusia itu sendiri. Dalam penelitian ini pada tingkat pengetahuan, sikap, dan tindakan anggota keluarga kurang dalam memutus rantai penularan penyakit TB Paru didalam rumah. Sehingga perilaku yang didapat dari keseluruhan juga kurang. Perilaku anggota keluarga yang kurang didasarkan dari tingkat pengetahuan yang kurang yaitu kurangnya suatu pendidikan yang diterima

Perilaku anggota keluarga yang dilakukan dalam upaya pencegahan yang dilakukan agar terhindar dari penyakit TB Paru diantaranya adalah dengan membiasakan pola hidup bersih dan sehat. Pola hidup bersih dan sehat sebenarya sudah diajarkan dalam agama Islam, di mana kebersihan adalah sebagian dari iman. Selain itu upaya pencegahan yang dilakukan adalah jika batuk harus tutup mulut, jika bersin menutup hidung dan tidak meludah di sembarangan tempat.

Kebiasaan anggota keluarga yang dianggap berkaitan dengan penularan penyakit adalah kebiasaan untuk tidak menutup mulut ketika batuk dan meludah di sembarangan tempat. Di samping itu faktor keadaan sanitasi rumah yang cenderung tidak memenuhi syarat seperti kebiasaan anggota keluarga yang cenderung menutup jendela rumah pada pagi dan siang hari sehingga udara dalam rumah tidak dapat tertukar dengan udara segar, cahaya matahari tidak bisa masuk kedalam rumah, rumah sangat lembap sehingga cepat menjadi pertumbuhan bakteri dan keadaan lingkungan sekitar yang kotor. 
Namun, masih ada juga perilaku anggota keluarga yang baik tetapi keadaan sanitasi rumah yang tidak memenuhi syarat hal ini bisa disebabkan karena responden memang bisa menjawab dengan tepat dan benar kuisioner yang telah diberikan tetapi pada fakta nya atau kenyataan nya keadaan sanitasi rumah mereka yang tidak memenuhi syarat karena kesibukan atau aktivitas sehari-hari sehingga tidak ada waktu untuk membersihkan rumah. Faktor ekonomi juga menjadi salah satu penyebab penghambat dan pendukung untuk Berdasarkan hasil penelitian tentang Hubungan Perilaku Anggota Keluarga dengan Keadaan Sanitasi Rumah untuk mencegah penularan TB Paru dalam rumah (Studi Kasus di Wilayah Kerja Puskesmas Wonokusumo Surabaya Tahun 2016 ) dapat disimpulkan bahwa :

1. Tingkat Pengetahuan anggota keluarga mengenai keadaan sanitasi rumah pada kriteria kurang dengan prosentase sebesar $51 \%$.

2. Sikap anggota keluarga mengenai keadaan sanitasi rumah pada kriteria kurang dengan prosentase sebesar $53,1 \%$.

3. Tindakan anggota keluarga mengenai keadaan sanitasi rumah pada kriteria kurang sebesar $46,9 \%$.

4. Keadaan sanitasi rumah yang tidak memenuhi syarat sebesar $61,2 \%$.

5. Ada hubungan antara tingkat pengetahuan anggota keluarga penderita TB Paru dengan keadaan sanitasi rumah untuk mencegah penularan TB Paru dalam rumah.

6. Ada hubungan antara sikap anggota keluarga penderita TB Paru dengan keadaan sanitasi rumah untuk mencegah penularan TB Paru dalam rumah

7. Ada hubungan antara tindakan anggota keluarga penderita TB Paru dengan keadaan sanitasi rumah untuk mencegah penularan TB Paru dalam rumah.

8. Ada hubungan antara perilaku anggota keluarga penderita TB Paru dengan keadaan sanitasi rumah untuk mencegah penularan TB Paru dalam rumah.

\section{SARAN}

Berdasarkan kesimpulan atas penelitian yang telah dilakukan di wilayah kerja puskesmas

\section{DAFTAR PUSTAKA}

Achmadi, U.F. 2012. Dasar-Dasar Penyakit Berbasis Lingkungan. Jakarta, Rajawali Pers.

Aviliana,R.Wenas.2015. Hubungan Perilaku Dengan Kejadian Penyakit Tb Paru menciptakan keadaan sanitasi rumah yang memenuhi syarat. Jika perilaku dan faktor ekonomi baik maka dapat meningkatkan keadaan sanitasi yang baik yang dapat menciptakan keadaan sanitasi rumah yang memenuhi syarat sehingga dapat mencegah terjadinya penularan penyakit didalam rumah khususnya penularan penyakit TB Paru.

\section{KESIMPULAN}

Wonokusumo Surabaya tahun 2016, peneliti menyarankan beberapa hal sebagai berikut :

1. Bagi Dinas Kesehatan dan Puskesmas

Meningkatkan pengetahuan anggota keluarga dengan cara memberikan penyuluhan mengenai penyakit TB Paru meliputi pengertian TB Paru, cara penularan, cara pencegahan dan cara pengobatan.

Meningkatkan pengetahuan anggota keluarga mengenai penyuluhan tentang sanitasi rumah yang dilakukan secara kotinyu. Memberikan motivasi, selalu menyebarkan media informasi melalui brosur, leaflet dan poster agar masyarakat dapat tersentuh dengan informasi TB Paru dan Sanitasi Rumah yang memenuhi syarat. Meningkatkan peran dan fungsi Kader pada saat penderita periksa/mengambil obat diberikan penyuluhan untuk selalu mengingatkan penderita agar meningkatkan kondisi sanitasi rumah untuk mencegah penularan penyakit TB Paru.

2. Bagi Masyarakat

Meningkatkan perilaku yang terkait dengan pencegahan penyakit TB Paru dalam rumah seperti menggunakan masker, menjaga kebersihan rumah dengan cara menyapu dan mengepel lantai menggunakan larutan lisol pembunuh kuman, membuka jendela setiap hari agar sinar matahari dapat masuk kedalam rumah dan suhu kelembapan dalam rumah tetap stabil. Mengadakan program kerja bakti secara rutin untuk pembersihan lingkungan sekitar rumah di tiap RT.

3. Bagi Peneliti lain

Mengembangkan penelitian ini pada beberapa faktor dan variabel lain yang dapat mempengaruhi perilaku dengan keadaan sanitasi rumah untuk mencegah penularan TB Paru dalam rumah.

Didesa Wori Kecamatan Wori Kabupaten Minahasa Utara. http://ejournal.unsrat.ac.id/index.php/] KKT/article/download/7776/7339. (Diakses pada tanggal 2 Juni 2016) 
Ditjen P2PL Kemenkes,RI.2014.Pedoman Nasional Pengendalian Tuberkulosis.

Khadijah Azhar dan Dian Perwitasari.2013. Kondisi Fisik Rumah Dan Perilaku Dengan Prevalensi Tb Paru Di Propinsi Dki Jakarta, Banten Dan Sulawesi Utara.

http://ejournal.litbang.depkes.go.id/ind ex.php/MPK/article/view/3427/3401.

(Diakses pada tanggal 01 Juni 2016).

Kasjono, Heru Subaris.2011. Penyehatan Pemukiman. Yogyakarta, Gosyen Publishing.

Kepmenkes, RI.2009. Undang-Undang No. 36 Tahun 1992 tentang Kesehatan.

Lumbang, Tonny. 2008. Pengaruh perilaku penderita TB Paru dan Kondisi Rumah Terhadap Pencegahan Potensi Penularan TB Paru dalam Keluarga di Kabupaten Tapanuli Utara. http://repository.usu.ac.id/bitstream/12 3456789/6656/1/09E01348.PDF. (Diakses pada tanggal 10 Januari 2016).

Media,Yulfira.2011. Pengetahuan, Sikap Dan Perilaku Masyarakat Tentang Penyakit Tuberkulosis (Tb) Paru Di Kecamatan Sungai Tarab, Kabupaten Tanah Datar Propinsi Sumatera Barat. http://ejournal.litbang.depkes.go.id/ind ex.php/mpk/article/download/108/89. (Diakses pada tanggal 5 Juni 2016)

Nadesul, Handrawan.1995. Penyebab, Pencegahan, dan Pengobatan TBC. Jakarta, PT Pustaka Pembangunan Swadaya Nusantara PUSPA SWARA.

Notoatmodjo, Soekidjo. 2011. Kesehatan Masyarakat IImu\&Seni. Jakarta, Rineka Cipta.

Notoatmodjo, Soekidjo.2014. IImu Perilaku Kesehatan . Jakarta, Rineka Cipta.

Putro, Eko. 2012. Teknik Penyusunan Instrumen Penelitian. Yogyakarta, Pustaka Pelajar.

Riandra, Niko. 2011. Hubungan perilaku dan kondisi sanitasi rumah dengan kejadian TB Paru di kota Solok. http://repository.unand.ac.id/16894/1/ Skripsi Lengkap Niko.pdf. (Diakses pada tanggal 11 Januari 2016).

Soedarto. 2013. Lingkungan dan Kesehatan Environment and Health. Jakarta, Sagung Seto.

Sugiyono. 2014. Metode Penelitian Kuantitatif Kualitatif dan R\&D. Bandung, Alfabeta.

Supardi, Sudibyo dan Surahman. 2014. Metodologi Penelitian. Trans Info Media.

Suyono dan Budiman, 2012. IImu Kesehatan Masyarakat Dalam Konteks Kesehatan Lingkungan. Jakarta, Buku Kedokteran EGC. 